Association for Information Systems

AIS Electronic Library (AISeL)

AMCIS 1999 Proceedings

Americas Conference on Information Systems

(AMCIS)

December 1999

\title{
Reengineering Comes To the Nonprofit Sector: A Case Study of Goodwill Industries of the Laurel Highlands Incorporated
}

James Rodger

University of Pittsburgh at Johnstown

Parag Pendharkar

Penn State Capital College

David Paper

Utah State University

Follow this and additional works at: http://aisel.aisnet.org/amcis 1999

\section{Recommended Citation}

Rodger, James; Pendharkar, Parag; and Paper, David, "Reengineering Comes To the Nonprofit Sector: A Case Study of Goodwill Industries of the Laurel Highlands Incorporated" (1999). AMCIS 1999 Proceedings. 234.

http://aisel.aisnet.org/amcis1999/234 


\title{
Reengineering Comes To the Nonprofit Sector: A Case Study of Goodwill Industries of the Laurel Highlands Incorporated
}

\author{
James A. Rodger, University of Pittsburgh at Johnstown \\ Parag C. Pendharkar, Penn State Capital College \\ David J. Paper, Utah State University
}

Introduction

Traditionally, not-for-profit organizations did not worry about management. "Twenty years ago, management was a dirty word for those involved in nonprofit organizations ... now most of them have learned that nonprofits need management even more than business does, precisely because they lack the discipline of the bottom line" (Drucker, 1989). Not-for-profit organizations are in the initial stages of using strategic management (Wortman, 1988; Bryson, 1988; Karagozoglu and Seglund, 1989; Harvey and McCrohan, 1988). Therefore, it is not surprising that reengineering and business process redesign have been given little attention by not-for-profits.

Goodwill Industries of the Laurel Highlands Incorporated (GILHI) is redesigning its retail operations by decentralizing all retail processing to its individual stores. Presently, all processing is handled at one centralized plant in Johnstown, PA. GILHI realizes that the radical changes it is attempting in its retail operations must be accompanied by radical changes in the way it manages information; to successfully transform its business. To improve enterprise-wide information and provide convenient, cost-effective retail delivery to its customers, GILHI is using point-of-sale (POS) technology and a just-in-time (JIT) inventory system. It hopes that redesign will. It is also radically changing its employment and training function to develop a wider base of customers. It wants to make the widest possible range of services available and develop and expand existing employment opportunities for customers.

\section{Research Question}

The purpose of the study is to gain insight into how a not-for-profit company approaches reengineering and implements redesigned business processes.

\section{BPR in Not-For-Profits}

To date, few in-depth case studies of BPR initiatives in the not-for-profit sector have appeared in MIS journals. The popular management literature has relied too much on hype and too little on research, common sense, and the lessons of the past (Davenport and Stoddard, 1994). Scholarly MIS journals have relied too much on drawing insights and conclusions from survey-based research, rather than in-depth case analysis. The few exceptions are reported here.

Caron et al. (1994) examined BPR initiatives at CIGNA for over five years. An extremely important insight generated from the CIGNA case study was to start small. CIGNA success was generated slowly. Once a pilot BPR study was shown to be successful, larger projects were undertaken. Davenport and Stoddard (1994) addressed various myths associated with BPR based on detailed case study analysis of many companies. The authors present a no-nonsense synthesis of their experiences in BPR in actual practice. They conclude that successful BPR is not an IT initiative. Rather, it is a business initiative with the goal of rethinking business practices to satisfy the needs of its customers and other constituents. Kotter (1995) synthesized information and knowledge gained from observations of more than 100 companies into a set of eight steps to facilitate organizational transformation.

\section{Inception of BPR at GILHI}

Goodwill Industries of the Conemaugh Valley, Inc., (GICVI) was incorporated in December, 1962. However, they have been slowly decentralizing operations to their stores in nearby counties. As a result (and to better represent its constituents in the communities served) GICVI changed its name to GILHI in early 1998. This was a direct result of ongoing BPR initiated in August 1997 by the CEO, Amy Luttrell.

As a first step to BPR, GILHI rewrote their mission to include "empower people with barriers to employment to become more self-sufficient through work." Its five-year plan includes opening retail outlets at three new sites. It believes that POS and JIT will facilitate delivery of services and information between the retail outlets.

\section{Methodology}

Case study research began with the in August, 1997. One of the authors serves on the Board of Directors of GILHI, and is the Chair of the Planning Committee. Data were gathered from interviews, GILHI annual reports, monthly financial statements, and from the GILHI World 
Wide Web site. Five GILHI executives were interviewed including the Director of Retail Operations, the Director of Employment and Training, the Director of Marketing and Development, the Director of Contracts, and the Director of Administrative Services. Contact is maintained via monthly Planning Committee and General Board of Director meetings. Each interview lasted approximately one hour. Open-ended questions were used to guide discussions.

\section{Interview Results}

Session One. The first session was with Susan Mock, Director of Administrative Services (AS). She is in charge of accounting/finance, human resources, and information technology (IT) and has in excess of 10 years of experience in the not-for-profit sector. Her BPR goal is "to create a model work environment that is value driven and provides smooth functioning administrative systems, including human resources, finance and information systems to assist the organization in achieving its mission."

With over 100 employees and thousands of customers, managing the volume of business was becoming inefficient at the six store sites. Management was also more difficult because each of the sites had its own way of doing business. With many ways of doing business, consistency, information accuracy, and communication was becoming harder to maintain. "We saw a need for radical change. Luckily, the top management team was ready and willing to commit resources and change policy where necessary." Another driver was the trend toward automation in the nor-for-profit industry. "We responded by adopting automated POS registers and a JIT inventory system to better serve customers. But we only automated after consideration for existing processes. We developed a separate Human Resources Department before going forward with a new human resource information system (HRIS) (for continuous tracking of employees. We also looked at the way we were administering customers before we automated."

BPR began with waste identification. "We noticed that independent processing at the 6 different stores was causing redundancies, overlap of work, and inaccurate information about volumes, sales and inventory. It was impossible to consolidate up-to-date and accurate information because the IT used at the different stores was either nonexistent or not integrated." Another problem was that retail operation is customer-driven not IT-driven. GILHI could not offer a full line of product sizes and styles such as coats, suits, and dresses because the AS function was not organized to accommodate a "multiproduct" paradigm.
The goal of BPR is to decentralize control of retail processing to the retail stores, streamline existing business processes, and decentralize IT and business processes to provide virtual service to customers and internal users. The role of IT will be to facilitate process streamlining after rethinking and decentralization of GILHI data.

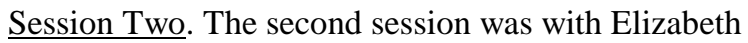
Sakmar, the Director of Marketing and Development $M \& D)$. She is responsible for strategic marketing information flow.

"M\&D facilitates BPR by informing and educating current employees about project status through monthly meetings. We hope that our BPR effort will promote agency-wide mission marketing by using subsidized billboards, by developing and covering all six county outlying regions, by developing agency literature and brochures, and by instituting an interactive Internet page and video machine."

"We liked the idea of starting with a project that had to work. It got everyone focused on task. We also liked our expanded role working directly as part of IT. This helped us learn more about each other and better understand the how the business works as an enterprise."

Session Three. The third session was with June Rose. June is charged with development and implementation of the warehousing technologies throughout GILHI.

"Information reengineering is very important to BPR at GILHI. The POS registry has provided many benefits for GILHI employees. Information sharing is much easier, more timely, and more accurate. The warehousing technologies allow decentralization of inventory."

BPR has increased efficiency in retail operations by causing us to review and revise the trucking schedules, by implementing a POS register and JIT inventory system, by decentralizing retail processing to the stores, and by implementing a plan for purchasing replacement trucks.

"At first, we were worried that marketing would try to push us around when a representative became a part of IT. It was tense at the beginning, but over time we realized that we had the same business goals and learned from each other."

Session Four. The fourth session was with Bill Tresise, who is in charge of GILHI contracts. The goal of contracts is to generate revenue and provide appropriate employment and training opportunities to support the GILHI mission. 
"BPR forced us to revisit our entire contracting process. It showed that our process was not properly aligned properly with our mission. We reacted by implementing new training curriculums, updating equipment, and expanding services. We also established new business ventures to serve as both revenue sources and training sites and to acquire in-house contracts."

Session Five. The fifth session was with Phyllis Bandstra (CEO of GILHI). "The real value of BPR was to enable our customers to achieve their fullest vocational potential, achieve desirable life outcomes, and function as contributing members of the community through provision of a wide range of opportunities. BPR forced us to look at ourselves and re-evaluate what was really important."

"To make BPR really work, we had to prepare and manage relevant service growth consistent with the mission. The difficult part was not alignment itself, but getting people to communicate and think about the business as a whole enterprise."

"A major change in our strategy was to staff the IT department with business managers. The main reason for this change was that our IT department had a legacy for providing technically elegant solutions that didn't always meet our business needs. We had confidence in IT, but we knew that they did not truly understand the business. Since we wanted IT to lead the effort, we wanted to give them the best chance of success."

"Another problem is integrating our IT and business strategy. We knew that IT must be strategic to make BPR work. We wanted IT management to become more involved in our strategic mission. With the addition of key business managers to IT, we opened up a channel of effective dialogue between top management and IT."

\section{Lessons Learned}

The qualitative study with GILHI provides many insights into how one not-for-profit company actually dealt with BPR on an enterprise-wide basis. However, one should keep in mind that the data is biased because we only interviewed top management.

Lession One. Business managers should work closely with the IT department. Each department worked with IT people to redefine its business processes.

Lession Two. A dual strategy of business and information reengineering is ideal. BPR concentrates on business processes, but IT can be an incredibly tool to facilitate effectiveness.
Lession Three. BPR should be based on a business need. GILHI chose to redesign its business processes because it was concerned about its reputation with its customers, not because it wanted to fire people or "appear" to be making changes. GILHI understood that its fundamental business paradigm was flawed.

Lesson Four. The IT department should lead the effort. Since information flow is a part of every core process, IT should lead change efforts. IT people are the only people who understand how information is used across the organization.

Lesson Five. BPR requires support from top management and those involved along the process path to succeed. If top management does not visibly support BPR, politics will destroy the project. Most people are afraid of change. Given the opportunity to resist change, many will do just that. Top management can lead the "political effort" and get everyone else involved.

Lession Six. The IT department must have business representatives. IT must have a feeling for the overall business if it is to serve all its clients. Therefore, top management should staff the IT department with business managers to add not-for-profit knowledge and experience.

Lesson Seven. Choose a pilot BPR project that must work so that its success can be sold to the rest of the company. Success is hard to resist. If a project is very successful, it will be much easier to get other departments and functional areas involved in BPR. Also, this strategy shows the organization that top management has real confidence in BPR.

\section{Acknowledgements}

This research was funded by the University Research Council small grants program at the University of Pittsburgh. The authors also wish to thank the members of the Board of Directors, the staff and management of GILHI for their patience and support in editing and "reengineering" this project.

\section{References Available upon request}

